\title{
Supplier selection in a sustainable supply chain
}

\begin{abstract}
Supplier selection is a process by which the firms identify, evaluate, and select the suppliers of their required raw materials. Although this process deploys an overwhelming amount of any firm's financial resources, it would give substantial advantages if suppliers with high value are selected. Moreover, with paying more attention to the exhaustible natural resources and industrial pollution, sustainable supply chain management and sustainable supplier selection have significantly attracted the academic and corporate attention in recent years. Besides conventional criteria such as price and quality, sustainability cares about environmental and ecological respects of industrial activities. Reviewing the literature and considering the previous proposed frameworks for sustainable supply chain, this paper firstly aims at presenting a new structure which considers all of the influential relations between the members of the supply chain. Secondly, based on the new framework, the essential supplier selection measures and criteria are discussed. As the result, the offered scheme can be used by the manufacturers to select the most appropriate suppliers who contribute to the movement of the supply chain toward sustainability.
\end{abstract}

Keyword: Supply chain management; Supplier selection; Sustainable development 